\title{
3D modeling of long-term slow slip events along the flat slab segment in the Guerrero Seismic Gap, Mexico
}

\author{
Andrea Perez-Silva ${ }^{1, *}$, Duo Li $^{1}$, Alice-Agnes Gabriel ${ }^{1}$, Yoshihiro Kaneko ${ }^{2}$ \\ ${ }^{1}$ Department of Earth and Environmental Sciences, Ludwig-Maximilians-Universität München, Germany \\ ${ }^{2}$ Department of Geophysics, Graduate School of Science, Kyoto University, Japan \\ *Now at Victoria University of Wellington, School of Geography, Environment and Earth Sciences, New \\ Zealand
}

\section{Key Points:}

- We model cycles of long-term slow slip events in the Guerrero Seismic Gap using a geometrically flexible 3D boundary integral method

- Our model reproduces the source characteristics and surface deformation of four longterm SSEs inferred from geodetic observations

- The flat segment of the Cocos plate likely aids the large magnitudes and long recurrence times of the slow slip events in Guerrero

Corresponding author: D. Li, dli@geophysik.uni-muenchen.de 


\section{Abstract}

During the last two decades, quasi-periodic long-term slow-slip events (SSEs) of magnitudes up to $\mathrm{M}_{\mathrm{w}} 7.5$ have been observed about every 4 years in the Guerrero Seismic Gap. Here we present numerical simulations of the long-term SSE cycles along the 3D slab geometry of central Mexico. Our model accounts for the hydrated oceanic crust in the framework of rate-and-state friction. The modeled SSE cycles capture the major source characteristics of the long-term SSEs occurring from 2001 to 2014, as inferred from geodetic observations. Synthetic surface deformation calculated from simulated fault slip is also in good agreement with the cumulative GPS displacements. Our results suggest that the flat segment of the Cocos plate aids the large magnitudes and long recurrence intervals of the long-term SSEs. We conclude that $3 \mathrm{D}$ slab geometry is an important factor in furthering our understanding of the physics of slow slip events.

\section{Plain Language Summary}

Slow slip events (so-called "silent earthquakes") have been detected worldwide in circum-Pacific subduction zones, e.g. Cascadia and southwest Japan. Long-term slow slip events occur about every 4 years in the Guerrero Seismic Gap (Mexico) where tectonic plate movement is largely accommodated by aseismic slip and no earthquakes have been observed since 1911. We build a numerical model incorporating a realistic 3D geometry of the subducting slab and lab-derived friction laws to investigate the physics of these slow slip events. The simulated cycles of events have slip patterns, magnitudes, and recurrence intervals comparable with the observed ones. The along-strike variation of slab dipping angle is significantly correlated to their source characteristics. Our study demonstrates that plate geometry is an important factor to account for when studying the initiation, propagation and arrest of slow slip. 


\section{Introduction}

Slow slip events (SSEs) are recurring, transient periods of aseismic slip on plate interfaces. SSEs occur predominantly at the edges of the seismogenic zone where the frictional regime transitions from stick-slip to stable-sliding behaviour (Dragert et al., 2001; Schwartz \& Rokosky, 2007; Wallace \& Beavan, 2010; Peng \& Gomberg, 2010; Radiguet et al., 2012). The discovery of SSEs has transformed our perception of how the long-term geological loading is released along plate boundaries, as these events can account for a significant fraction of the accumulated strain (Schwartz \& Rokosky, 2007; Peng \& Gomberg, 2010; Wallace \& Beavan, 2010; Radiguet et al., 2012). Observations, numerical modeling, and laboratory experiments suggest that several factors, such as pore fluid pressure, thermal structure, rock composition, slab geometry, and rheological complexity, may influence the dynamics of SSEs (Scholz, 1998; Y. Liu \& Rice, 2005; Audet et al., 2009; Wech \& Creager, 2011; Wei et al., 2013, 2018; Hyndman, 2013; Saffer \& Wallace, 2015; D. Li \& Liu, 2016; McLaskey \& Yamashita, 2017).

In central Mexico, long-term SSEs have been detected quasi-episodically in the northwestern part of the Guerrero Seismic Gap (GSG) (Kostoglodov et al., 2003; Vergnolle et al., 2010; Radiguet et al., 2012), which is a 100-km segment that has not experienced large earthquakes since 1911 (Kostoglodov et al., 2003) (red bar in Figure 1). Continuous GPS recordings show that these SSEs occur every $\sim 4$ years, last from several months up to one year and release elastic energy equivalent to up to $\sim \mathrm{M}_{\mathrm{w}} 7.5$ earthquakes (Lowry et al., 2001; Kostoglodov et al., 2003; Radiguet et al., 2012), ranking among the largest SSEs worldwide. Smaller $\left(\mathrm{M}_{\mathrm{w}} 6.6\right.$ - 6.9) and more frequent SSEs (1 - 2 years) occur in Oaxaca state, $\sim 300 \mathrm{~km}$ southeastward of GSG (blue contour in Figure 1); some events also propagate in the region between Oaxaca and Guerrero (Graham et al., 2016). Short-term SSEs and non-volcanic tremors (NVTs) have been identified in the vicinity of the downdip edge of the long-term SSEs in Guerrero (Husker et al., 2012; Frank et al., 2015a; Rousset et al., 2017; Maury et 
al., 2018; Husker et al., 2019). All of these observations highlight the diversity of slow slip behavior in central Mexico.

Receiver functions and seismic velocity tomography along the broadband Meso-American Subduction Experiment (MASE) array (MASE, 2007) reveal a sub-horizontal segment of the downgoing Cocos plate beneath the Guerrero region (Pérez-Campos et al., 2008; Husker \& Davis, 2009; Kim et al., 2010). This flat-slab segment may be due to ongoing continental crust hydration and weakening, a process that started 15 Ma ago (Manea \& Manea, 2011). High pore fluid pressure has been inferred atop of the sub-horizontal segment (Jödicke et al., 2006; Song et al., 2009; Kim et al., 2010), which may result in a particularly favourable environment for SSEs and NVTs (Song et al., 2009; Manea \& Manea, 2011).

Here we investigate the importance of $3 \mathrm{D}$ variations in slab geometry for the dynamics of SSEs in Guerrero. We perform numerical simulations of long-term SSEs using a realistic 3D slab geometry of the Cocos plate in central Mexico. The model incorporates a laboratoryderived rate-and-state friction law and assumes near-lithostatic pore pressure conditions at SSE source depths. We compare modeled long-term SSE source characteristics and surface deformation with geodetic inversion results from two-decade long continuous GPS recordings. We discuss the emergence of smaller SSEs at the along-strike transition from flat to steeper slab. Our model has important implications for our fundamental understanding of the physics of long-term SSEs in relation to slab geometry and strength.

[Figure 1 about here.]

\section{Methods and model setup}

We follow the modeling approach of D. Li and Liu (2016), where a non-planar fault is embedded into an elastic half-space. This model implements a quasi-dynamic approach to relate shear traction and fault slip (Supplementary Text S1). We incorporate the laboratoryderived rate-and state-dependent friction law (Ruina, 1983; Dieterich, 1979, 2007) to constrain yielding and slip on the prescribed slab interface. The shear strength of the fault, $\tau$, 
depends logarithmically on the slip rate $V$ and a state variable $\theta$, which can be interpreted as the temporal evolution of the state of asperity contacts (Dieterich, 1979; Ruina, 1983), as

$$
\tau=\bar{\sigma} f=\bar{\sigma}\left[f_{0}+a \ln \left(\frac{V}{V_{0}}\right)+b \ln \left(\frac{V_{0} \theta}{d_{c}}\right)\right]
$$

where $f$ is the friction coefficient, $f_{0}$ is the steady state friction coefficient at reference slip rate $V_{0}, d_{c}$ is the critical slip distance over which a fault loses or regains its frictional strength after a perturbation in the loading conditions and $a$ and $b$ are dimensionless constitutive parameters. The frictional stability regime of the fault is either velocity-strengthening $(a-$ $b>0)$ or velocity-weakening $(a-b<0)$. The effective normal stress is $\bar{\sigma}$, and is defined as the difference between the lithostatic normal stress $\left(\sigma_{n}\right)$ and the pore fluid pressure $\left(p_{f}\right)$, with $\bar{\sigma}=\sigma_{n}\left(1-\lambda_{p}\right)$ and $\lambda_{p}=p_{f} / \sigma_{n}$.

In this study, the temporal evolution of the state variable is described by the 'aging' law, which assumes that the state variable $\theta$ increases monotonously with time for stationary contacts as supported by lab experiments (Dieterich, 1979):

$$
\frac{d \theta}{d t}=1-\frac{V \theta}{d_{c}}
$$

The corresponding, upper-limit of critical nucleation size $\left(h^{*}\right)$ is defined from the fracture energy balance for an expanding crack (Rubin \& Ampuero, 2005), as

$$
h^{*}=\frac{2 \mu b d_{c}}{\pi(1-\nu) \bar{\sigma}(b-a)^{2}},
$$

where we assume shear modulus $\mu=30 \mathrm{GPa}$ and Poisson ratio $\nu=0.25$.

We incorporate the 3D plate geometry of the Cocos plate obtained using the dense broadband seismic array from Pérez-Campos et al. (2008). The model domain extends $430 \mathrm{~km}$ along the Cocos - North America plate boundary and covers a depth range from 10 to $60 \mathrm{~km}$ (Figure 2a). The slab is assumed locked from the trench to $15 \mathrm{~km}$ depth and 
allowed to slip between 15 and $60 \mathrm{~km}$ depth. We define a uniform plate convergence velocity that is directed $\mathrm{N} 63^{\circ} \mathrm{E}$ at a rate of $V_{p l}=6.1 \mathrm{~cm} / \mathrm{yr}$ (DeMets et al., 2010). The slab geometry is discretized into triangular elements with edge lengths no longer than $1500 \mathrm{~m}$ using the commercial software Cubit/Trelis (https://www. coreform.com/).

The depth distribution of $(a-b)$ (Figure $2 \mathrm{~b})$ onto the 3D slab interface is obtained by converting the temperature-dependent wet gabbro gouges data (He et al., 2007) using the 2D steady state thermal model of Central Mexico from Manea and Manea (2011). Velocitystrengthening conditions $((a-b)>0)$ are also imposed at the edges of the model domain to stabilize slip at the plate convergence rate (Figure S1).

Following previous studies (e.g., Y. Liu \& Rice, 2007; D. Li \& Liu, 2016; Shibazaki et al., 2019), we account for the inferred high pore fluid pressure condition atop the Cocos plate where SSEs occur (Jödicke et al., 2006; Song et al., 2009; Kim et al., 2010) by assuming low effective normal stress $\bar{\sigma}$ at SSE source region. $\bar{\sigma}$ is set to be $50 \mathrm{MPa}$ except for a lower value of $2.5 \mathrm{MPa}$ at depths between 20 and $45 \mathrm{~km}$. We refer to the depth range of low $\bar{\sigma}$ as the "SSE zone" (Figure 2b). The model parameter $W$ is defined as the width of the downdip distance on the fault under velocity-weakening and low $\bar{\sigma}$ condition (Figure $2 \mathrm{~b}$ ).

The ratio $W / h^{*}$ has been shown to be a key parameter that controls the periodic behaviors of the fault and the emergence of SSEs (Y. Liu \& Rice, 2007; Barbot, 2019). Previous studies have also shown that $W / h^{*} \sim 1$ reproduces slow slip characteristics in Cascadia (Y. Liu \& Rice, 2007; D. Li \& Liu, 2016). Here we vary $W$ and $h^{*}$ independently and analyse SSE source characteristics (recurrence, magnitude and slip velocity) for each parameter configuration (Supplementary Text S2). The simulation assuming $W / h^{*}=1.18$ $\left(d_{c}=10.1 \mathrm{~mm}\right)$ is selected as the preferred model since it best reproduces the characteristics and geodetic signature of long-term SSEs. In the following we describe the results of this simulation. Other parametrizations and the respective sensitivities are discussed in Supplementary Text S2. 


\section{Results}

\subsection{Spatio-temporal evolution of slip rate}

The model produces spontaneous slow slip events under long-term geodetic loading until a seismic event, $V>5 \mathrm{~mm} / \mathrm{s}$, occurs after 145 years. The slip rate varies by several orders of magnitude on the fault as shown in Figure 3a (see also Figures S5 and S6). Rupture migrating fronts where $V>3 V_{p l}$ (green contours in Figure 3a) indicate the occurrence of slow slip events . In the time interval between these events the fault is locked at the rate from $0.03 \mathrm{~V}_{p l}$ to $0.1 \mathrm{~V}_{p l}$ (dark blue areas in Figure 3a).

In this model, we identify three types of SSEs with different along-strike extent. Type I events rupture most of the slab along-strike, extending approximately $300 \mathrm{~km}$ (purple arrows in Figure 3a). The evolution of these events starts with a slow nucleation phase at two distant along-strike positions $(y=150 \mathrm{~km}$ and $y=-150 \mathrm{~km}$ ), from which two slip fronts migrate towards each other (converging white arrows in Figure 3a). The slip fronts merge into a velocity peak $\left(\mathrm{V}>10^{2} V_{p l}\right)$, where most of the slip accumulates; afterwards they propagate bilaterally (diverging white arrows in Figure 3a). During the bilateral propagation, the peak velocities of the slip fronts are lower $\left(\sim 3 V_{p l}\right)$. These characteristic features of slip rate evolution during one episode resemble a three-stage evolution (preparation, fast-spreading and relaxation) as observed in earlier Cascadia SSEs simulations (D. Li \& Liu, 2016), and correspond to non-linear fault stress release over time. The migration fronts of these events are asymmetric, in that the slip front migrates slightly slower and over a longer distance westwards than eastwards.

Type II events show a similar evolution pattern to Type I SSEs, except for a shorter along-strike extent (150-200 km) and a more symmetric migration path (black arrows in Figure 3a). Type III events have the shortest along-strike extent $(<100 \mathrm{~km})($ red arrows in Figure 3a). These events slip slower at velocities only 3 to 10 times the plate convergence 
rate $V_{p l}$ (Figure 3a). Type II and type III events can occur synchronously characterized by two distinct velocity peaks along-strike (e.g. the SSE during year 20 in Figure 3a).

The slip rate evolution changes moderately along-strike over time; the longest SSEs (Type I and II) nucleate mostly in the eastern part of the fault $(y<0 \mathrm{~km})$ whereas the shortest (Type III) SSEs initiate mostly in the western part $(y>0 \mathrm{~km})$. The along-strike variation is detailed in Figure $3 \mathrm{c}$ that shows the slip rate at two points on the fault (P1 and P2, colored circles in Figure 3a,d). At point P2, peak slip velocities are one to two orders of magnitude lower than at point P3. The time interval between these peaks is between 2 and 3 years, which is shorter than the average 4-year period at point $\mathrm{P} 1$. The along-strike change in the slip rate evolution intensifies in the next 50 simulation years (Figure S5), where we observe a persistent emergence of Type III SSEs in the western part of the fault, between 50 to $150 \mathrm{~km}$ along-strike; whereas Type I and II events concentrate further to the east.

\section{[Figure 3 about here.]}

\subsection{Comparison with geodetic observations}

We compare the preferred long-term SSE cycle model with geodetic inversion in terms of duration, magnitude and time interval in the period between 10 to 50 years simulation time. We select the modeled SSEs that occur within the GSG and calculate their source properties assuming a slip threshold of $10 V_{p l}$ (i.e., $1.93 \times 10^{-8} \mathrm{~m} / \mathrm{s}$ ). The SSE duration is defined as the time period over which this slip velocity threshold is exceeded. We then calculate the total cumulative slip and moment magnitude within the inferred duration. The recurrence time is given by the time interval in between the peak slip rates of successive SSEs. We assume a minimum slip of $1 \mathrm{~cm}$ to calculate the SSE magnitude, consistent with the threshold used in geodetic inversion (Radiguet et al., 2012).

Our modeled SSEs capture the major characteristics of the four long-term SSEs that occurred in 2001/2002, 2006, 2009/2010 and 2014, as inferred from geodetic inversion. They 
have an average duration, magnitude and recurrence interval of $8.7 \pm 3$ months, $\mathrm{M}_{\mathrm{w}} 7.44 \pm$ 0.08 , and $4.2 \pm 0.2$ years, respectively; all within the range of observations (Radiguet et al., 2012, 2016; Graham et al., 2016), as shown in Table S1. Figure S2 shows daily time series at GPS station CAYA and the cumulative slip at a fault node projected vertically from the station. The modeled recurrence interval agrees well with that indicated by the permanent geodetic records.

To further validate the modeled SSEs, we show in Figure 4 the slip distribution of four modeled SSEs that best capture the characteristics of the four long-term SSEs in Guerrero as constrained by geodetic inversions (Radiguet et al., 2012). Movies S1-S4 show the dynamic slip rate evolution of these four modeled SSEs. The respective synthetic surface deformation is calculated from the modeled SSE fault slip distributions assuming a homogeneous elastic half-space. We apply a Green's function for triangular elements (Meade, 2007). Horizontal and vertical displacement vectors are shown in Figure 4. We separate the horizontal and vertical components due to the observationally often larger noise level in the vertical records.

We define a misfit function as

$$
\chi^{2}=\frac{1}{N} \sum_{j=0}^{N}\left|\vec{S}_{j}^{o b s}-{\overrightarrow{S_{j}}}^{\text {mod }}\right|^{2},
$$

where $\vec{S}^{\text {mod }}$ and $\vec{S}^{\text {obs }}$ are the modeled and observed GPS displacement vectors at the $j$ th station and $N$ is the number of stations that detect the SSEs within our model domain. We quantify the respective misfits in Figure 4. The synthetic vectors match magnitude and direction of observations reasonably well, although the direction of the horizontal components along the coast shows a slight anti-clockwise rotational offset. The latter may indicate additional secondary strike-slip contributing to the observed displacements while we assume pure trench-normal slip in the model.

[Figure 4 about here.] 
The modeled SSEs exhibit along-strike migration rates of $0.5 \pm 0.3 \mathrm{~km} /$ day, which is comparable to the slow migration speeds $(0.8 \mathrm{~km} /$ day) reported for the $2006 \mathrm{SSE}$ (Radiguet et al., 2011), but lower than the 6 - $9 \mathrm{~km} /$ day estimated during the 2002 SSE (Kostoglodov et al., 2003). Low migration speeds, close to our model results, have also been reported for both observed and modeled long-term SSEs in Upper Cook Inlet in Alaska (Fu et al., 2015; H. Li et al., 2018), and in southwest Japan (Z. Liu et al., 2010).

\subsection{Long-term slip budget}

To estimate the long-term slip budget within the GSG from our SSE cycle model, we sum up the cumulative slip released after ten SSEs cycles ( $\sim 40$ years) and divide this total cumulative slip by the total amount of slip accumulated due to plate convergence over the same period. The total slip released (Figure 3d) is calculated as follows:

$$
\xi=\left(V_{p l} T\right)^{-1} \sum_{i=1}^{N} \delta_{i},
$$

where $N=10$ and $\delta_{i}$ is the accumulative slip in each episode. The slip deficit equals to $1-\xi$

We find that within the GSG, the fault releases $~ 80 \%$ of the plate convergence loading via slow slip. This result is slightly higher than the geodetic inferences in Radiguet et al. (2012), which indicate that SSEs release $75 \%$ of the accumulated strain within the GSG over three SSE cycles.

\subsection{Moment-duration scaling relation}

We calculate the moment-duration scaling relation of the modeled SSEs (triangles in Figure 3e) assuming a velocity threshold of $10 V_{p l}$ (i.e. $1.93 \times 10^{-8} \mathrm{~m} / \mathrm{s}$ ) and a threshold slip of $1 \mathrm{~cm}$ to calculate the moment. The best-fit scaling of the modeled SSEs follows $\mathrm{M} \sim \mathrm{T}^{1.76}$. The moment and duration of the four long-term SSE episodes reported by Radiguet et al. $(2012,2016)$ fall within the upper bound of our model (red stars in Figure 3e)). The wider 
range in magnitude and duration of modeled SSEs may result from the different spatiotemporal behaviours of all three types of SSEs as described in Section 3.1. This scaling relation changes only slightly when including more events with different $h^{*}$ values $(\mathrm{M} \sim$ $\mathrm{T}^{1.56}$ in Figure $\left.\mathrm{S} 7\right)$.

\section{Discussion}

\subsection{Geometric effects on the source properties of SSEs}

The emergence of long-term SSEs of large magnitudes, $\mathrm{M}_{\mathrm{w}} \geq 7.0$, observed along the flat-slab shallowly dipping segment beneath Guerrero suggests that variations in fault geometry may play a key role in understanding the variability of slow slip dynamics (e.g., (Brudzinski et al., 2016; Maury et al., 2018). Our numerical findings support the importance of 3D slab geometry in demonstrating the spontaneous emergence of realistic SSE cycles considering a realistic fault geometry. In our model, the velocity-weakening portion of the fault under near-lithostatic pore fluid pressure conditions (defined as $W$ ) is inversely correlated to the average dipping angle at specific depths $(20-45 \mathrm{~km})$. As a result, $W$ varies significantly between 60 and $160 \mathrm{~km}$ along strike, as shown Figure 3b.

Previously modeled SSE source characteristics (e.g. recurrence, slip rate, cumulative slip, etc.) roughly scale with $W / h^{*}$ (Y. Liu \& Rice, 2009). In our preferred model, $h^{*}$ is kept constant along the entire slab and the relatively large $W$ is a dominant factor that leads to large magnitudes and long recurrence times characterizing long-term SSE dynamics in Guerrero. We perform additional simulations, which confirm the effect of $W$. Increasing $W$ by $6 \mathrm{~km}$, which represents only $4 \%$ of its preferred value $(\mathrm{W}=144.4 \mathrm{~km})$, leads to an increase in the median periodicity, magnitude, and peak slip rate of the emerging SSEs (Figure S4). Thus, even small changes in this parameter have an effect on the characteristics of modeled SSEs.

The lateral curvature of the slab influences the shear stress evolution on the fault. In previous models, larger cumulative SSE tends to appear where the fault is flatter, and 
steepening of the slab promotes SSE arrest (D. Li \& Liu, 2016). Here, we additionally find that the lateral patterns of the modeled SSEs, especially smaller events appearing on the western part of the fault, vary moderately over time; this can be seen by comparing the along-strike migration patterns of SSEs shown in Figure 3a, Figure S5 and Figure S6. This along-strike variation reflects an additional effect of the non-planar fault (Matsuzawa et al., 2013), as the western part of the fault has narrower $W$, which promotes more frequent and smaller SSEs (e.g. Y. Liu \& Rice, 2009).

Another key factor potentially governing long-term slow slip behaviour is the ultraslow velocity layer (USL) imaged on the top of the Cocos plate, which is attributed to a high pore fluid layer beneath both the Guerrero and Oaxaca regions (Song et al., 2009; Dougherty \& Clayton, 2014). The effect of the USL is incorporated in our model by the high pore fluid pressure assigned on the fault between 20-45 km. In central Mexico, the relatively shallow dipping angle (e.g., $\sim 12$ between $20-45 \mathrm{~km}$ in Figure S8) of the Cocos plate compared with the neighbouring region may facilitate active dehydration reactions along a wider portion atop the slab (Manea \& Manea, 2011), and thus promote long-term slow slip occurrence and low-frequency earthquakes (LFEs) accompanied with short-term SSEs on the downdip portion (Frank et al., 2015b).No obvious SSEs have been reported in the more flat southeastern segment of GSG based on current geodetic network (Radiguet et al., 2012; Cruz-Atienza et al., 2020). The absence of SSEs may be attributed to the less coupled fault interface from geodetic inversion (Radiguet et al., 2016) and the lack of USL from seismic imaging (Song et al., 2009; Dougherty \& Clayton, 2014).

\subsection{Implications for diverse slow slip along central Mexico}

In our preferred SSE cycle model, smaller SSEs nucleate in the northwest of the GSG $\left(\sim 101.5^{\circ} \mathrm{W}\right.$ to $\left.\sim 103.5^{\circ} \mathrm{W}\right)$. These Type III SSEs (see Section 3.1) have lower slip rate and shorter along-strike extent than those nucleating eastward (Figure 3a). Between 2001 and 2014, however, no slip was detected in the northwestern region (Maury et al., 2018), while our model suggests that this region might have slipped during these long-term SSEs. We note 
that the modeled Type III SSEs may be below current observational detection thresholds. Recent time-dependent GPS modeling of the $2019 \mathrm{M}_{\mathrm{w}} 7.0$ SSE resolved aseismic slip in the northwestern GSG (Cruz-Atienza et al., 2020), implying that this region may host slow slip.

The here presented model does not include short-term SSEs associated with lowfrequency earthquakes (LFEs) at the so-called sweet spot further down-dip (Husker et al., 2012; Frank et al., 2015a), due to the lack of geodetic constraints. This along-dip variation of SSE recurrence may reflect the pore fluid increasing with depth modulated by temperaturedependent silica deposition as suggested by seismic imaging in northern Cascadia (Audet \& Burgmann, 2014). Additional application of our modeling approach may help to understand the along-dip variation in SSE source characteristics in future work.

One puzzling aseismic slip observation in southern Mexico is the occurrence of smaller and more frequent SSEs in Oaxaca state, southeast of Guerrero (blue contours in Figure 1). In Oaxaca, the ultra-low velocity layer extends only $100 \mathrm{~km}$ from the trench, whereas in Guerrero it extends as far as $150 \mathrm{~km}$ (Song et al., 2009). Based on our findings, this may translate into a narrower downdip distance of the SSE zone (i.e. a narrower $W$ ), which then can explain the nucleation of smaller and more frequent SSEs beneath Oaxaca, as this factor roughly scales with the source properties of our modeled SSEs (Figure S4). On the other hand, the convergence rate of the Cocos plate under the North American plate increases southeastwards (DeMets et al., 2010), which may also contribute to the shorter recurrence period of SSEs in Oaxaca, as plate convergence rate has been shown to inversely correlate with the recurrence times of simulated SSEs (Shibazaki et al., 2012; Watkins et al., 2015; H. Li et al., 2018).

\subsection{Implications for source scaling relation}

Our scaling falls in between the $M \sim T^{3}$ scaling found for a wide range of regular earthquakes (Kanamori \& Anderson, 1975) and the $M \sim T$ scaling inferred from a global compilation of SSEs (Ide et al., 2007). The differences in scaling relations between slow 
slip and regular earthquakes has been documented for many subduction zones (Ide et al., 2007; Peng \& Gomberg, 2010; Gao et al., 2012) and is typically attributed to fundamental differences in the underlying physical mechanisms. However, for the four long-term SSEs inferred from geodetic inversion (Radiguet et al., 2012, 2016) observational scaling remains difficult to constrain due to the narrow spread in magnitude and duration (Figure 3e).It has been shown that simultaneous SSEs tend to have a different scaling relation than temporally non-overlapping, distinct SSEs, regardless of fault geometry and friction properties (Y. Liu, 2014). Future work should include smaller SSEs further downdip and further validate the here reported source scaling relations.

Recently, a cubic moment-duration scaling has been reported for the Nankai (Takagi et al., 2019), Cascadia (Michel et al., 2019) and Mexico (Frank \& Brodsky, 2019) subduction zones from geodetic and seismic observations. We note that an apparent shift of the scaling from $M \sim T$ to $M \sim T^{3}$ may result from breaking a large slow slip event (as the $2006 \mathrm{SSE}$ ) into a cluster of disparate daily slow transients calibrated by seismic LFE records (Frank \& Brodsky, 2019). The identification based on cut-off slip rate may also considerably influence the geodetically resolved moment-duration scaling (D. Li \& Liu, 2017). Our results suggest that the separation between the two scaling relations may be not distinct. Rather, dynamic variability of natural fault slip (Peng \& Gomberg, 2010) may also reflect in, potentially regional specific, continuous variability in SSE scaling relations.

\section{Conclusions}

We present the first 3D sequence simulations of long-term slow slip events within the Guerrero Seismic Gap, Mexico. Our model accounts for a realistic 3D fault geometry and laboratory-derived rate-and-state friction, and assumes the presence of high-fluid pressure regions atop the subducting slab at SSE source depths, supported by the existence of ultralow velocity layer revealed by high-resolution seismic imaging. The simulation produces spontaneously emerging long-term SSEs under constant geological plate convergence. 
Our preferred model successfully reproduces the main source characteristics of longterm SSEs along the flat-slab segment beneath Guerrero as well as surface deformation obtained from two-decade continuous GPS recordings. In particular, we find that the source characteristics, including duration, magnitude, slip pattern, and recurrence interval of the simulated SSEs agree well with those of the long-term SSEs detected from 2001 to 2014 within Guerrero. Four modeled events match the inverted slip distribution and GPS displacements reasonably well. Our model results suggest that the unusually large magnitudes $\left(\mathrm{M}_{\mathrm{w}} \geq 7.0\right)$ and long recurrence intervals ( $\sim 4$ years) of SSEs in Guerrero are favored by the shallow dipping, Cocos plate flat-slab segment.

In addition, three distinct types of SSEs emerge in the model, which have variable along-strike extents, ranging from $<100$ to $300 \mathrm{~km}$. The smallest events concentrate on the western margin where the downdip width of the SSE zone is narrower. This suggests that along-strike changes in the slab dip angle may significantly affect SSE characteristics. Modeled SSEs follow a moment-duration scaling of $M \sim T^{1.76}$, which is between the originally proposed linear scaling and the recently reported cubic relation for SSEs in Nankai, Cascadia and Mexico. Future work may be directed towards understanding the origin of the scaling trend of both long-term and short-term SSEs in Guerrero and Oaxaca, Mexico.

\section{Acknowledgments}

The model parameter setup and simulation data is available at https://doi.org/10.5281/ zenodo.4561753. The work presented in this paper was supported by the European Research Council (ERC) under the European Union's Horizon 2020 research and innovation programme (ERC Starting Grant TEAR agreement No. 852992), the German Research Foundation (DFG project grants no. GA 2465/2-1, GA 2465/3-1)) and the Rutherford Discovery Fellowship from the Royal Society of New Zealand. Computing resources were provided by the Institute of Geophysics of LMU Munich (Oeser et al., 2006) and the Leibniz Supercomputing Centre (LRZ, projects no. pr63qo and pr45fi on SuperMUC). We thank Dr. Mathilde Radiguet for kindly sharing the GPS inversion results of the Guerrero slow slip 
events. We appreciate the fruitful discussions with Dr. Luis Dalguer and the Seismology group at Munich University (LMU). DL initialized the project and created the mesh file. AP performed all simulations and created figures under the supervision of DL and AG. All authors contributed to the discussion of the results and writing of the manuscript.

\section{References}

Audet, P., Bostock, M. G., Christensen, N. I., \& Peacock, S. M. (2009). Seismic evidence for overpressured subducted oceanic crust and megathrust fault sealing. Nature, 457, 76-78. doi: $0.1038 /$ nature 07650

Audet, P., \& Burgmann, R. (2014). Possible control of subduction zone slow-earthquake periodicity by silica enrichment. Nature, 510, 389-393. doi: 10.1038/nature13391

Barbot, S. (2019). Slow-slip, slow earthquakes, period-two cycles, full and partial ruptures, and deterministic chaos in a single asperity fault. Tectonophysics, 768, 228171. doi: 10.1016/j.tecto.2019.228171

Brudzinski, M. R., Schlanser, K. M., Kelly, N. J., DeMets, C., Grand, S. P., Márquez-Azúa, B., \& Cabral-Cano, E. (2016). Tectonic tremor and slow slip along the northwestern section of the Mexico subduction zone. Earth and Planetary Science Letters, 454, 259-271. doi: 10.1111/j.1365-246X.2007.03542.x

Cruz-Atienza, V. M., Tago, J., Villafuerte, C., Wei, M., Garza-Girón, R., Dominguez, L. A., . . others (2020). Short-Term Interaction between Silent and Devastating Earthquakes in Mexico. Earth and Space Science Open Archive, 53. doi: 10.1002/essoar.10503980.1

DeMets, C., Gordon, R. G., \& Argus, D. F. (2010). Geologically current plate motions. Geophysical Journal International, 181(1), 1-80. doi: 10.1111/j.1365-246X.2009.04491 . $\mathrm{x}$

Dieterich, J. (1979). Modeling of rock friction 1. Experimental results and constitutive equations. Journal of Geophysical Research, 84(B5), 2161-2168. doi: 10.1029/ JB084iB05p02161

Dieterich, J. (2007). Applications of rate-and state-dependent friction to models of fault- 
slip and earthquake occurrence. Treatise on Geophysics, 4, 107-129. doi: 10.1016/ B978-044452748-6.00065-1

Dougherty, S. L., \& Clayton, R. W. (2014). Seismicity and structure in central Mexico: Evidence for a possible slab tear in the South Cocos plate. J. Geophys. Res., 119(4), 3424-3447. doi: 10.1002/2013jb010883

Dragert, H., Wang, K., \& James, T. S. (2001). A silent slip event on the deeper Cascadia subduction interface. Science, 292(5521), 1525-1528. doi: 10.1126/science.1060152

Fasola, S., Brudzinski, M. R., Ghouse, N., Solada, K., Sit, S., Cabral-Cano, E., ... Jensen, K. (2016). New perspective on the transition from flat to steeper subduction in Oaxaca, Mexico, based on seismicity, nonvolcanic tremor, and slow slip. Journal of Geophysical Research, 121(3), 1835-1848. doi: 10.1002/2015JB012709

Frank, W. B., \& Brodsky, E. E. (2019). Daily measurement of slow slip from low-frequency earthquakes is consistent with ordinary earthquake scaling. Science Advances, 5(10), eaaw9386. doi: 10.1126/sciadv.aaw9386

Frank, W. B., Radiguet, M., Rousset, B., Shapiro, N., Husker, A., Kostoglodov, V., ... Campillo, M. (2015a). Uncovering the geodetic signature of silent slip through repeating earthquakes. Geophysical Research Letters, 42, 2774-2779. doi: 10.1002/ $2015 \mathrm{gl} 1063685$

Frank, W. B., Shapiro, N., Husker, A., Kostoglodov, V., Bhat, H., \& Campillo, M. (2015b). Along-fault pore-pressure evolution during a slow-slip event in Guerrero, Mexico. Earth and Planetary Science Letters, 413, 135-143. doi: 10.1016/j.epsl.2014.12.051

Fu, Y., Liu, Z., \& Freymueller, J. T. (2015). Spatiotemporal variations of the slow slip event between 2008 and 2013 in the southcentral Alaska subduction zone. Geochemistry, Geophysics, Geosystems, 16(7), 2450-2461. doi: 10.1002/2015GC005904

Gao, H., Schmidt, D. A., \& Weldon, R. J. (2012). Scaling relationships of source parameters for slow slip events. Bulletin of the Seismological Society of America, 102(1), 352-360. doi: $10.1785 / 0120110096$

Graham, S., DeMets, C., Cabral-Cano, E., Kostoglodov, V., Rousset, B., Walpersdorf, A., 

... Salazar-Tlaczani, L. (2016). Slow Slip History for the MEXICO Subduction Zone: 2005 Through 2011. Pure and Applied Geophysics, 173, 3445-3465. doi: 10.1007/ 978-3-319-51529-8_13

Gualandi, A., Perfettini, H., Radiguet, M., Cotte, N., \& Kostoglodov, V. (2017). GPS deformation related to the $\mathrm{M}_{\mathrm{w}} 7.3$, 2014, Papanoa earthquake (Mexico) reveals the aseismic behavior of the Guerrero seismic gap. Geophysical Research Letters, 44 (12), 6039-6047. doi: 10.1002/2017g1072913

He, C., Wang, Z., \& Yao, W. (2007). Frictional sliding of gabbro gouge under hydrothermal conditions. Tectonophysics, 445, 353-362. doi: 10.1016/j.tecto.2007.09.008

Husker, A., \& Davis, P. M. (2009). Tomography and thermal state of the Cocos plate subduction beneath Mexico City. Journal of Geophysical Research: Solid Earth, 114, B04306. doi: 10.1029/2008JB006039

Husker, A., Frank, W. B., Gonzalez, G., Avila, L., Kostoglodov, V., \& Kazachkina, E. (2019). Characteristic tectonic tremor activity observed over multiple slow slip cycles in the Mexican subduction zone. Journal of Geophysical Research: Solid Earth, 124(1), 599-608. doi: 10.1029/2018JB016517

Husker, A., Kostoglodov, V., Cruz-Atienza, V. M., Legrand, D., Shapiro, N. M., Payero, J. S., . . Huesca-Pérez, E. (2012). Temporal variations of non-volcanic tremor (NVT) locations in the Mexican subduction zone: Finding the NVT sweet spot. Geochemistry, Geophysics, Geosystems, 13, Q03011. doi: 10.1029/2011GC003916

Hyndman, R. D. (2013). Downdip landward limit of Cascadia great earthquake rupture. Journal of Geophysical Research: Solid Earth, 118(10), 5530-5549. doi: 10.1002/ jgrb.50390

Ide, S., Beroza, G. C., Shelly, D. R., \& Uchide, T. (2007). A scaling law for slow earthquakes. Nature, 447(7140), 76-79. doi: 10.1038/nature05780

Jödicke, H., Jording, A., Ferrari, L., Arzate, J., Mezger, K., \& Rüpke, L. (2006). Fluid release from the subducted Cocos plate and partial melting of the crust deduced from magnetotelluric studies in southern Mexico: Implications for the generation of 
volcanism and subduction dynamics. Journal of Geophysical Research, 111, B08102. doi: $10.1029 / 2005 J B 003739$

Kanamori, H., \& Anderson, D. L. (1975). Theoretical basis of some empirical relations in seismology. Bulletin of the Seismological Society of America, 65(5), 1073-1095. doi: 10.1002/2014JB011144

Kim, Y., Clayton, R. W., \& Jackson, J. M. (2010). Geometry and seismic properties of the subducting Cocos plate in central Mexico. Journal of Geophysical Research: Solid Earth, 115, B06310. doi: 10.1029/2009JB006942

Kostoglodov, V., Singh, S. K., Santiago, J. A., Franco, S. I., Larson, K. M., Lowry, A. R., \& Bilham, R. (2003). A large silent earthquake in the Guerrero seismic gap, Mexico. Geophysical Research Letters, 30(15), 1807. doi: 10.1029/2003GL017219

Li, D., \& Liu, Y. (2016). Spatiotemporal evolution of slow slip events in a nonplanar fault model for northern Cascadia subduction zone. Journal of Geophysical Research: Solid Earth, 121(9), 6828-6845. doi: 10.1002/2016JB012857

Li, D., \& Liu, Y. (2017). Modeling slow-slip segmentation in Cascadia subduction zone constrained by tremor locations and gravity anomalies. Journal of Geophysical Research: Solid Earth, 122(4), 3138-3157. doi: 10.1002/2016JB013778

Li, H., Wei, M., Li, D., Liu, Y., Kim, Y., \& Zhou, S. (2018). Segmentation of slow slip events in south central Alaska possibly controlled by a subducted oceanic plateau. Journal of Geophysical Research: Solid Earth, 123(1), 418-436. doi: 10.1002/2017JB014911

Liu, Y. (2014). Source scaling relations and along-strike segmentation of slow slip events in a 3-D subduction fault model. Journal of Geophysical Research: Solid Earth, 119(8), 6512-6533. doi: doi.org/10.1002/2014JB011144

Liu, Y., \& Rice, J. R. (2005). Aseismic slip transients emerge spontaneously in threedimensional rate and state modeling of subduction earthquake sequences. Journal of Geophysical Research: Solid Earth, 110, B08307. doi: 10.1029/2004JB003424

Liu, Y., \& Rice, J. R. (2007). Spontaneous and triggered aseismic deformation transients in a subduction fault model. Journal of Geophysical Research: Solid Earth, 112, B09404. 
doi: 10.1029/2007JB004930

Liu, Y., \& Rice, J. R. (2009). Slow slip predictions based on granite and gabbro friction data compared to GPS measurements in northern Cascadia. Journal of Geophysical Research, 114, B09407. doi: 10.1029/2008JB006142

Liu, Z., Owen, S., Dong, D., Lundgren, P., Webb, F., Hetland, E., \& Simons, M. (2010). Integration of transient strain events with models of plate coupling and areas of great earthquakes in southwest Japan. Geophysical Journal International, $181(3)$, 12921312. doi: 10.1111/j.1365-246X.2010.04599.x

Lowry, A. R., Larson, K. M., Kostoglodov, V., \& Bilham, R. (2001). Transient fault slip in Guerrero, southern Mexico. Geophysical Research Letters, 28(19), 3753-3756. doi: 10.1029/2001GL013238

Manea, V. C., \& Manea, M. (2011). Flat-Slab Thermal Structure and Evolution Beneath Central Mexico. Pure and Applied Geophysics, 168(8), 1475-1487. doi: 10.1007/ s00024-010-0207-9

MASE. (2007). Meso America subduction experiment. Caltech. Dataset.

Matsuzawa, T., Shibazaki, B., \& Hirose, H. (2013). Comprehensive model of short- and long-term slow slip events in the Shikoku region of Japan, incorporating a realistic plate configuration. Geophysical Research Letters, 40(19), 5125-5130. doi: 10.1002/ $\operatorname{grl} .51006$

Maury, J., Ide, S., Cruz-Atienza, V. M., \& Kostoglodov, V. (2018). Spatiotemporal variations in slow earthquakes along the Mexican subduction zone. Journal of Geophysical Research: Solid Earth, 123(2), 1559-1575. doi: 10.1002/2017JB014690

McLaskey, G. C., \& Yamashita, F. (2017). Slow and fast ruptures on a laboratory fault controlled by loading characteristics. Journal of Geophysical Research, 122(5), 37193738. doi: 10.1002/2016JB013681

Meade, B. J. (2007). Algorithms for the calculation of exact displacements, strains, and stresses for triangular dislocation elements in a uniform elastic half space. Computers and Geosciences, 33(8), 1064-1075. doi: 10.1016/j.cageo.2006.12.003 
Michel, S., Gualandi, A., \& Avouac, J.-P. (2019). Similar scaling laws for earthquakes and Cascadia slow-slip events. Nature, 574(7779), 522-526. doi: 10.1038/s41586-019-1673 $-6$

Oeser, J., Bunge, H.-P., \& Mohr, M. (2006). Cluster design in the earth sciences tethys. In International conference on high performance computing and communications (pp. $31-40)$.

Peng, Z., \& Gomberg, J. (2010). An integrated perspective of the continuum between earthquakes and slow-slip phenomena. Nature Geoscience, 3, 599-607. doi: 10.1038/ ngeo940

Pérez-Campos, X., Kim, Y., Husker, A., Davis, P. M., Clayton, R. W., Iglesias, A., .. Gurnis, M. (2008). Horizontal subduction and truncation of the Cocos Plate beneath central Mexico. Geophysical Research Letters, 35, L18303. doi: 10.1029/2008GL035127

Radiguet, M., Cotton, F., Vergnolle, M., Campillo, M., Valette, B., Kostoglodov, V., \& Cotte, N. (2011). Spatial and temporal evolution of a long term slow slip event: the 2006 Guerrero Slow Slip Event. Geophysical Journal International, 184(2), 816-828. doi: 10.1111/j.1365-246X.2010.04866.x

Radiguet, M., Cotton, F., Vergnolle, M., Campillo, M., Walpersdorf, A., Cotte, N., \& Kostoglodov, V. (2012). Slow slip events and strain accumulation in the Guerrero gap, Mexico. Journal of Geophysical Research: Solid Earth, 117, B04305. doi: 10.1029/ 2011JB008801

Radiguet, M., Perfettini, H., Cotte, N., Gualandi, A., Valette, B., Kostoglodov, V., ... Campillo, M. (2016). Triggering of the $2014 \mathrm{M}_{w} 7.3$ Papanoa earthquake by a slow slip event in Guerrero, Mexico. Nature Geoscience, 9(11), 829-833. doi: 10.1038/ ngeo2817

Rousset, B., Campillo, M., Lasserre, C., Frank, W. B., Cotte, N., Walpersdorf, A., ... Kostoglodov, V. (2017). A geodetic matched filter search for slow slip with application to the Mexico subduction zone. Journal of Geophysical Research: Solid Earth, 122(12), 10-498. doi: 10.1002/2017JB014448 
Rubin, A. M., \& Ampuero, J.-P. (2005). Earthquake nucleation on (aging) rate and state faults. Journal of Geophysical Research, 110, B11312. doi: 10.1029/2005JB003686

Ruina, A. L. (1983). Slip instability and state variable friction laws. Journal of Geophysical Research, 88(B12), 10,359-10,370. doi: 10.1029/JB088iB12p10359

Saffer, D. M., \& Wallace, L. M. (2015). The frictional, hydrologic, metamorphic and thermal habitat of shallow slow earthquakes. Nature Geoscience, 8(8), 594-600. doi: $10.1038 /$ ngeo2490

Scholz, C. H. (1998). Earthquakes and friction laws. Nature, 391(6662), 37-42. doi: $10.1038 / 34097$

Schwartz, S. Y., \& Rokosky, J. M. (2007). Slow slip events and seismic tremor at circum-Pacific subduction zones. Reviews of Geophysics, 45, RG3004. doi: 10.1029/ 2006RG000208

Shibazaki, B., Obara, K., Matsuzawa, T., \& Hirose, H. (2012). Modeling of slow slip events along the deep subduction zone in the Kii Peninsula and Tokai regions, southwest Japan. Journal of Geophysical Research, 117, B06311. doi: 10.1029/2011JB009083

Shibazaki, B., Wallace, L. M., Kaneko, Y., Hamling, I., Ito, Y., \& Matsuzawa, T. (2019). Three-dimensional modeling of spontaneous and triggered slow-slip events at the Hikurangi subduction zone, New Zealand. Journal of Geophysical Research: Solid Earth, 124(12), 13250-13268. doi: 10.1029/2019JB018190

Song, T. R., Helmberger, D. V., Brudzinski, M. R., Clayton, R. W., Davis, P., PerezCampos, X., \& Singh, S. K. (2009). Subducting slab ultra-slow velocity layer coincident with silent earthquakes in southern Mexico. Science, 324(5926), 502-6. doi: 10.1126/ science.1167595

Takagi, R., Uchida, N., \& Obara, K. (2019). Along-strike variation and migration of long-term slow slip events in the western Nankai subduction zone, Japan. Journal of Geophysical Research: Solid Earth, 124(4), 3853-3880. doi: 10.1029/2018JB016738

Vergnolle, M., Walpersdorf, A., Kostoglodov, V., Tregoning, P., Santiago, J. A., Cotte, N., \& Franco, S. I. (2010). Slow slip events in Mexico revised from the processing 
of 11 year GPS observations. Journal of Geophysical Research, 115, B08403. doi: 10.1029/2009JB006852

Wallace, L. M., \& Beavan, J. (2010). Diverse slow slip behavior at the Hikurangi subduction margin, New Zealand. Journal of Geophysical Research, 115, B12402. doi: 10.1029/ 2010JB007717

Watkins, W. D., Colella, H. V., Brudzinski, M. R., Richards-Dinger, K. B., \& Dieterich, J. H. (2015). The role of effective normal stress, frictional properties, and convergence rates in characteristics of simulated slow slip events. Geophysical Research Letters, 42(4), 1061-1067. doi: 10.1002/2014GL062794

Wech, A. G., \& Creager, K. C. (2011). A continuum of stress, strength and slip in the Cascadia subduction zone. Nature Geoscience, 4(9), 624-628. doi: 10.1038/ngeo1215

Wei, M., Kaneko, Y., Liu, Y., \& McGuire, J. J. (2013). Episodic fault creep events in California controlled by shallow frictional heterogeneity. Nature Geoscience, 6, 566570. doi: $10.1038 /$ ngeo1835

Wei, M., Kaneko, Y., Shi, P., \& Liu, Y. (2018). Numerical modeling of dynamically triggered shallow slow slip events in New Zealand by the $2016 \mathrm{Mw} 7.8$ Kaikoura earthquake. Geophysical Research Letters, 45(10), 4764-4772. doi: 10.1029/2018GL077879 


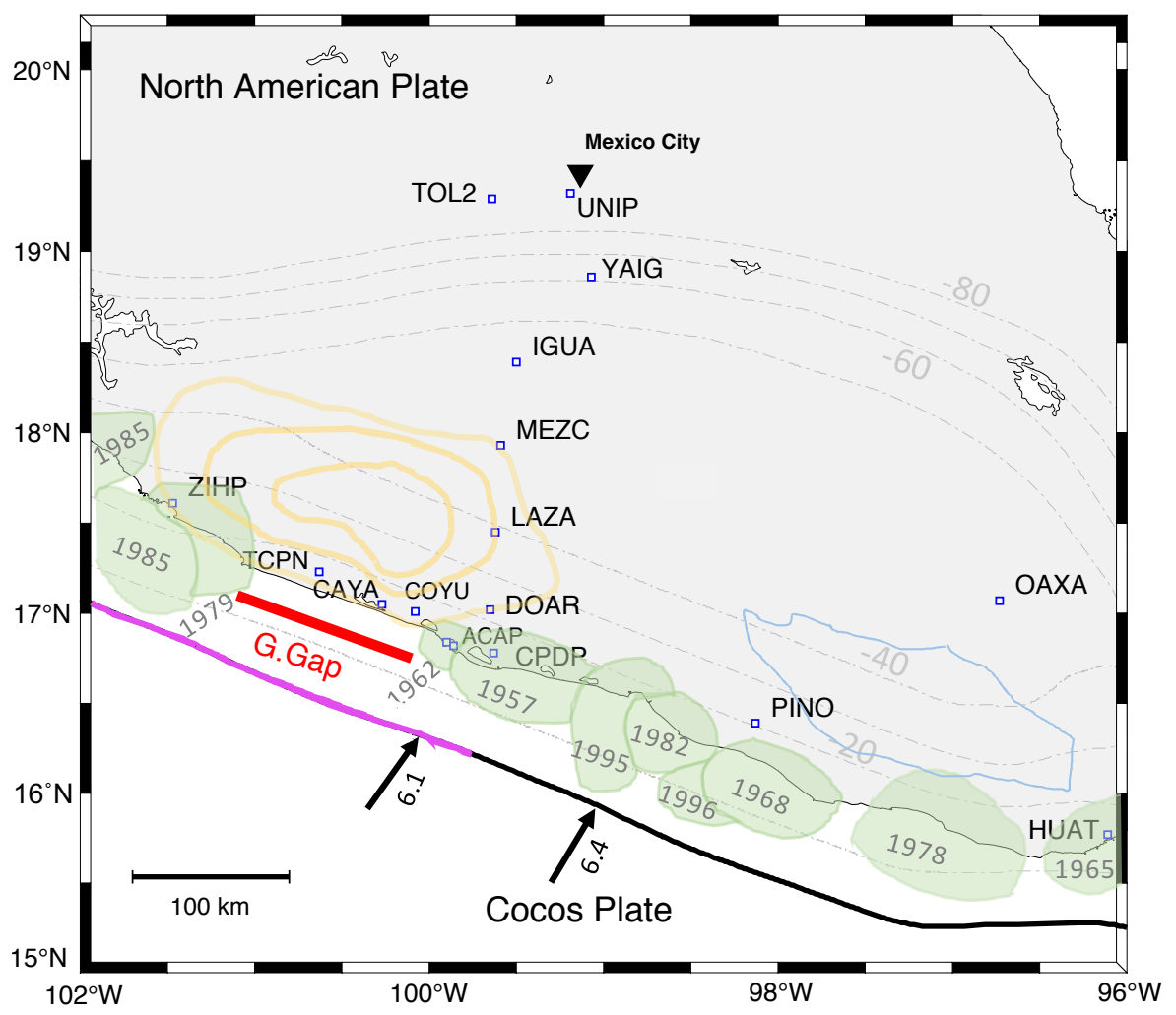

Figure 1. Map of the the Mexican subduction zone defined by the convergence of the Cocos and North American plates. The red bar highlights the northwestern portion of the Guerrero Seismic Gap extending $100 \mathrm{~km}$ along the strike. Green patches indicate the rupture area of historical earthquakes and the years of their occurrence (adapted from Fig. 1 in Radiguet et al. (2012)). Black arrows show direction and rate (in cm/yr) of plate convergence (DeMets et al., 2010). Yellow contours represent the mean cumulative slip of SSEs in 2001/2002, 2006 and 2010 from Radiguet et al. (2012), with 10-cm slip increment, starting at $20 \mathrm{~cm}$. The blue contour denotes the location of SSEs in the Oaxaca segment from Fasola et al. (2016). Gray dashed lines indicate the 10-km spacing depth contours of the Cocos plate from Pérez-Campos et al. (2008), with tags at every $20 \mathrm{~km}$. Blue squares denote regional permanent GPS stations. The thick black line indicates the location of the trench; its magenta part highlights the along-strike extension of the subduction model used in this study and detailed in Figure 2. 

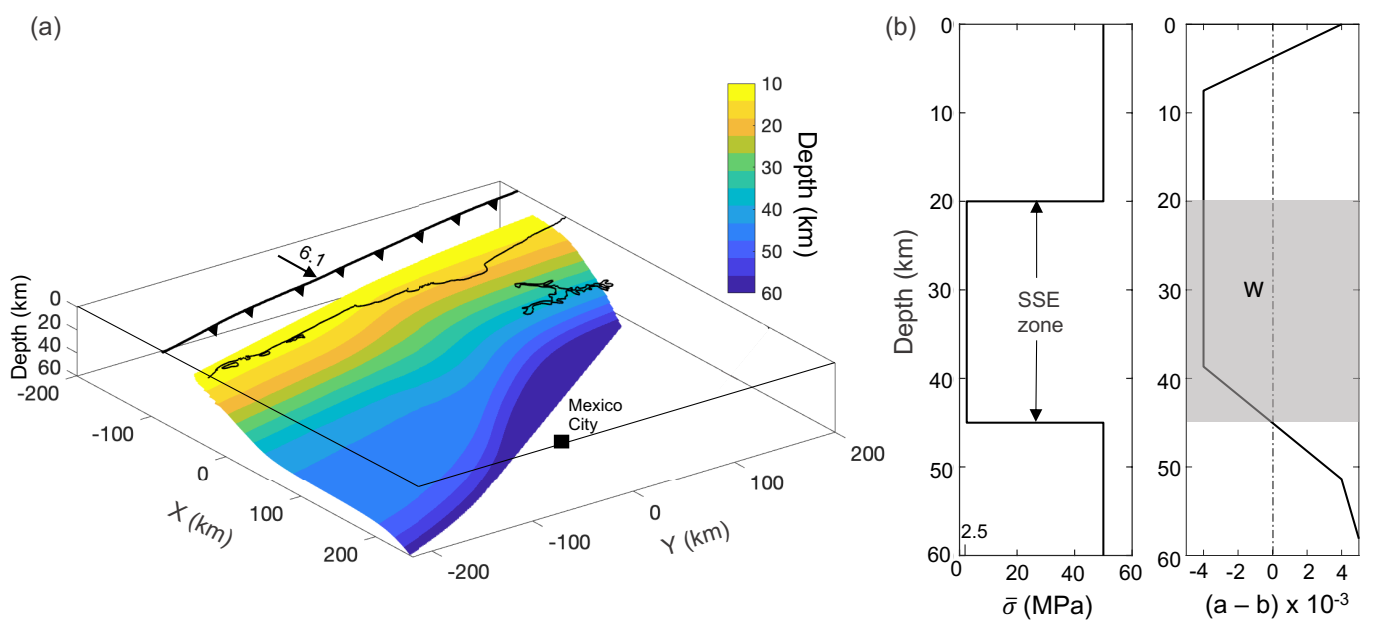

Figure 2. (a) Diagram of the 3D non-planar Cocos plate based on Pérez-Campos et al. (2008). The fault extents $430 \mathrm{~km}$ along the strike (see magenta line in Figure 1) and from 10 to $60 \mathrm{~km}$ in depth. The black arrow indicates relative plate motion (in $\mathrm{cm} / \mathrm{yr}$ ) taken from the PVEL model (DeMets et al., 2010). The black jagged line indicates the trench. The black square shows the location of Mexico City. (b) Depth profiles of effective normal stress $(\bar{\sigma})$ and friction parameter $(a-b)$. The $S S E$ zone refers to the depth range of $\bar{\sigma}=2.5 \mathrm{MPa}$. The gray shaded area represents the velocity-weakening region $(a-b<0)$ under low effective normal stress $(W)$ 

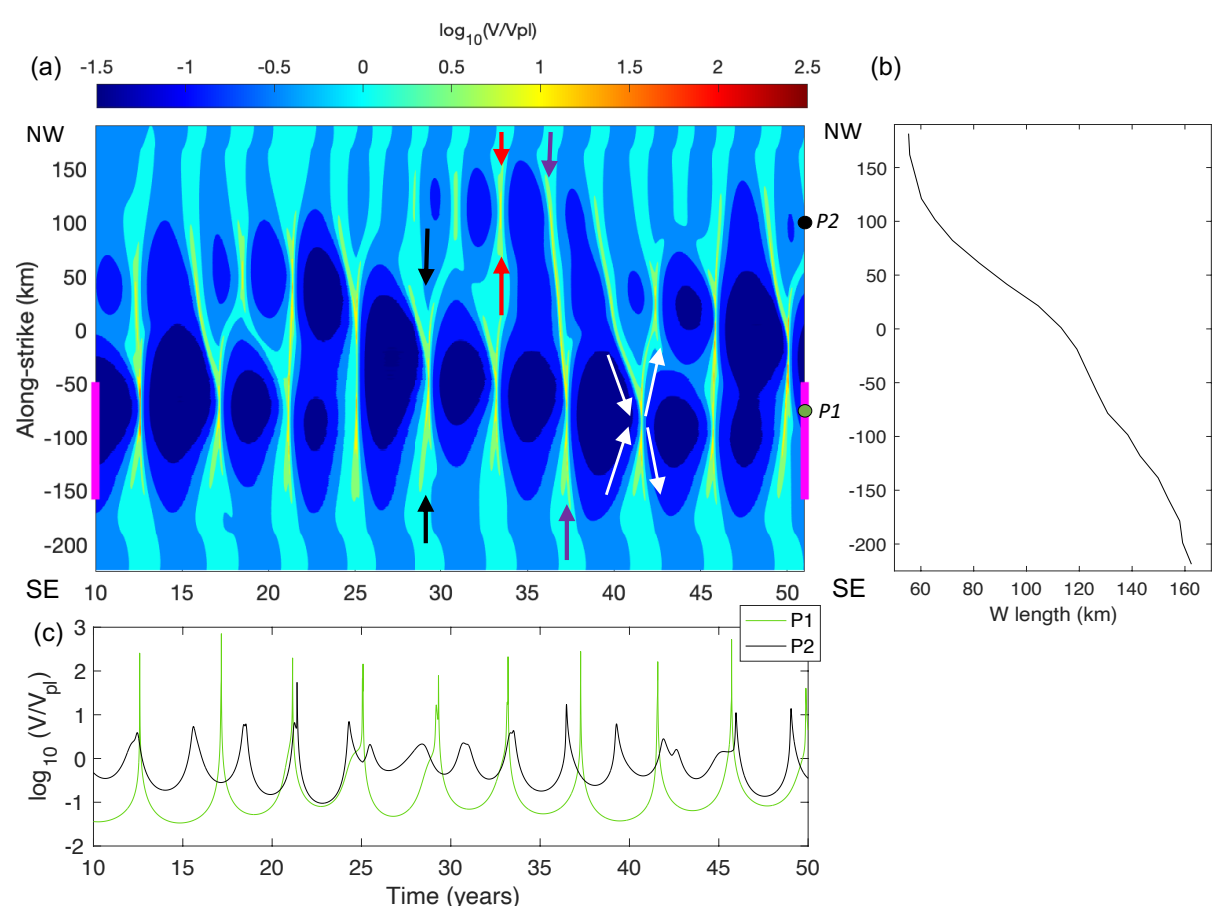

(d)

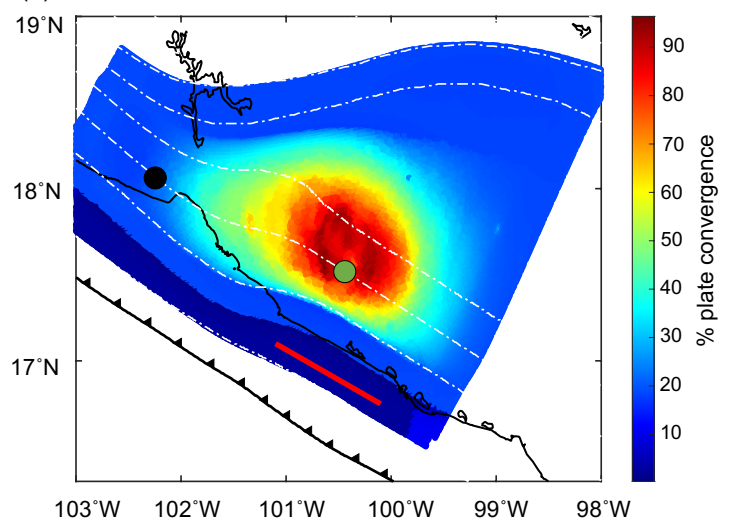

(e)

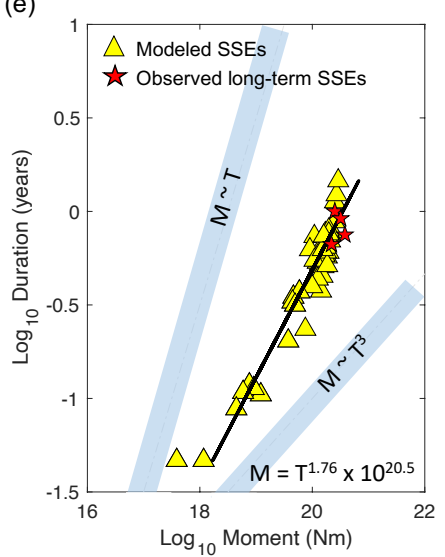

Figure 3. (a) Spatio-temporal evolution of slip rate at $30 \mathrm{~km}$ depth in $\log _{10}\left(V / V_{p l}\right)$ scale. Thick magenta lines indicate the northwestern GSG. Purple, black and red arrows point to the three types of SSEs decribed in the text. White arrows indicate the migration of slow slip fronts. (b) $W$ length (downdip distance on the fault surface) along-strike for the SSE zone between 20 and $45 \mathrm{~km}$ depth. (c) Slip rate at points P1 and P2 in the same period in (a) (location shown in (a) and (d)).(d) Slip released during ten modeled long-term SSEs as a percentage of total plate convergence. The dashed white line outlines the depth contours from 20 to $60 \mathrm{~km}$ depth. The red line highlights the location of the GSG. Green and black colored circles indicate locations of points P1 and P2, respectively. (e) Moment-duration scaling relation of 47 modeled SSEs over 145 simulation years (yellow triangles). Red stars indicate the data from four long-term SSEs in Guerrero (2001/2002, 2006, 2009/2010, 2014) taken from Radiguet et al. (2012, 2016). Best fit scaling of modeled SSEs shown in black $\left(\mathrm{M} \sim \mathrm{T}^{1.76}\right) . \mathrm{M} \sim \mathrm{T}$ and $\mathrm{M} \sim \mathrm{T}^{3}$ scaling is shown as reference. 

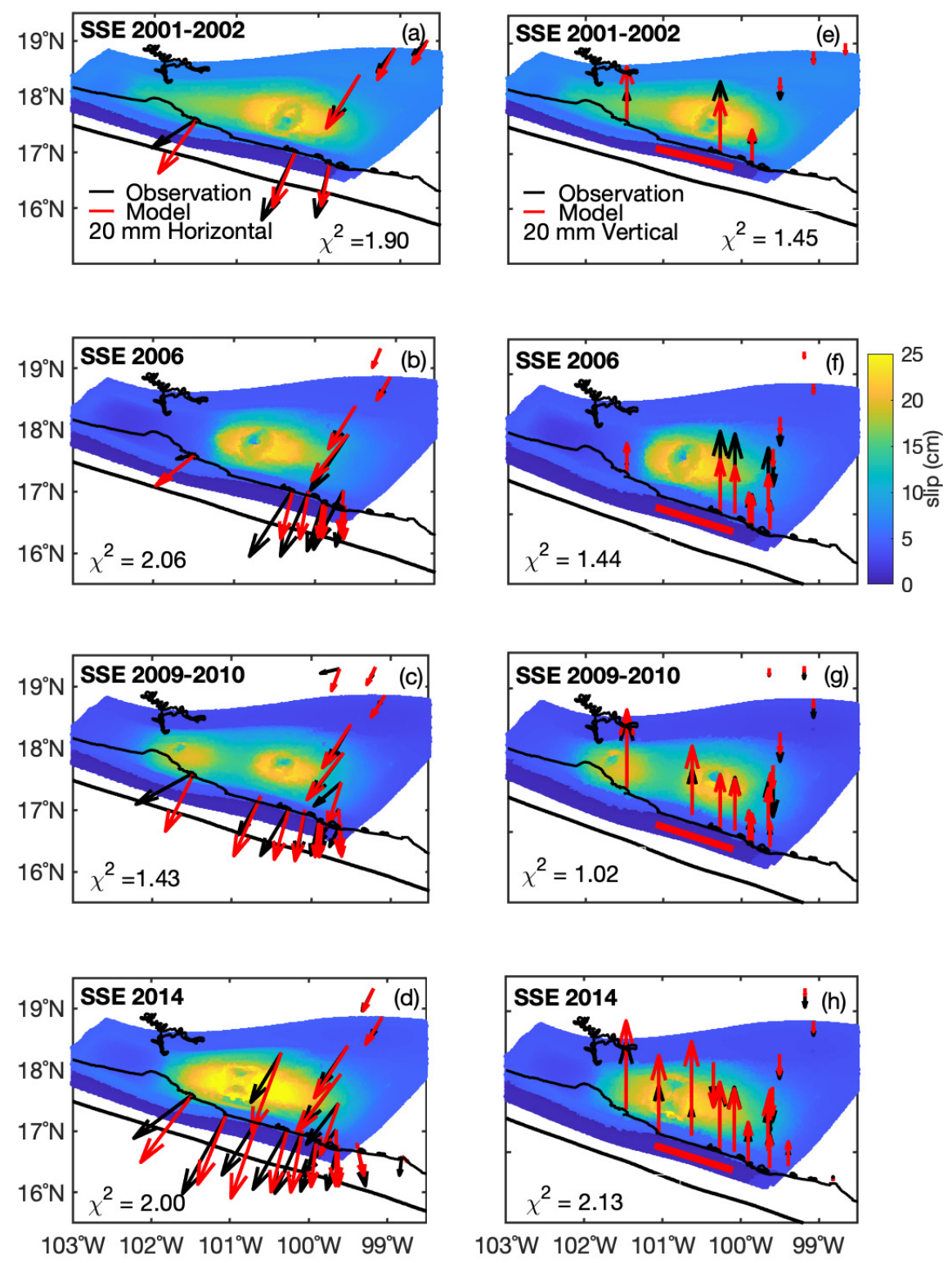

Figure 4. Modeled slip distribution and comparison between synthetic (red) and observed (black) GPS displacement vectors of the four SSE episodes of 2001/2002 (a and e), 2006 (b and f), 2009/2010 (c and g) and 2014 (d and h). (a)-(d) Horizontal surface displacements of the four episodes, respectively. Black arrows are GPS displacements inferred from observation (Radiguet et al., 2012; Gualandi et al., 2017). Red arrows are synthetic GPS displacements. (e)-(h) Vertical surface displacements. The thick red line indicates the GSG. The thick black line denotes the Middle American Trench. Depth contours are the same as in Figure 3c. Each plot reports $c h i^{2}$, the misfit of synthetic and observational data, as defined in Eq.4. 